\title{
Predictors of incorrectness in antimicrobial prescription in the Bauru State Hospital (Bauru city, São Paulo State, Brazil)
}

Thesis: G. H. Kawanami submitted this thesis for his Masters in Tropical Diseases at the Botucatu Medical School, São Paulo State University (UNESP - Univ Estadual Paulista), Botucatu, São Paulo State, Brazil, 2010.

Advisor: Professor Carlos Magno Castelo Branco Fortaleza

ABSTRACT: The inappropriate use of antimicrobials in hospitals presents a negative impact on patient outcome and is associated with the emergence and spread of multidrug-resistant microorganisms. Antimicrobial stewardship programs (ASPs) have been instituted in order to improve the quality of prescriptions in hospitals. In this setting, the identification of patterns of inappropriate antimicrobial prescription is a valuable tool that allows ASPs to identify priorities for directing educative/restrictive policies. With this purpose, a study was conducted in the Bauru State Hospital, a teaching hospital with 285 beds affiliated to the Botucatu Medical School, São Paulo State University. The hospital maintains an active ASP since it was opened, in 2002. We selected $25 \%$ of the requests for parenteral antimicrobials (RPAs) from 2005 for analysis. Prescriptions for prophylactic purposes were excluded. All other RPAs were classified according to a modified Kunin and Jones categories. Univariate and multivariable analyses were performed to identify predictors of general inappropriateness and of specific prescription errors. Prescriptions classified as "appropriate" or "probably appropriate" were selected as controls in all stages of the study. Among 963 RPAs included in our study, 34.6\% were inappropriate. General predictors of inappropriateness were: prescription on weekends/holidays $(\mathrm{OR}=1.67$, $95 \% \mathrm{Cl}=1.20-2.28, \mathrm{p}=0.002)$, patient from intensive care unit $(\mathrm{OR}=1.57,95 \% \mathrm{Cl}=$ 1.11-2.23, $\mathrm{p}=0.01)$, peritoneal $(\mathrm{OR}=2.15,95 \% \mathrm{Cl}=1.27-3.65, \mathrm{p}=0.004)$ or urinary tract infection $(\mathrm{OR}=1.89,95 \% \mathrm{Cl}=1.25-2.87, \mathrm{p}=0.002)$, combined therapy with two or more antimicrobials $(\mathrm{OR}=1.72,95 \% \mathrm{Cl}=1.15-2.57, \mathrm{p}=0.008)$ and prescriptions 
including penicillin $(\mathrm{OR}=2.12,95 \% \mathrm{Cl}=1.39-3.25, \mathrm{p}=0.001)$ or first-generation cephalosporins $(\mathrm{OR}=1.74,95 \% \mathrm{Cl}=1.01-3.00, \mathrm{p}=0.048)$. Previous consultation with an infectious diseases (ID) specialist had a protective effect against inappropriate prescription $(\mathrm{OR}=0.34,95 \% \mathrm{Cl}=0.24-0.50, \mathrm{p}<0.001)$. Factors independently associated with specific prescription errors varied. However, consultation with an ID specialist was protective against both unnecessary antimicrobial use $(\mathrm{OR}=0.04,95 \% \mathrm{Cl}=0.01-0.26, \mathrm{p}=0.001)$ and requests for agents with insufficient spectrum $(\mathrm{OR}=0.14,95 \% \mathrm{Cl}=0.03-0.30, \mathrm{p}=0.01)$. In conclusion, the analysis of factors predictive of inappropriateness in antimicrobial prescription allowed us to identify issues requiring intervention. Also, it provided a positive feedback of the ASP efficacy, demonstrating the importance of previous consultation with an ID specialist to assure the quality of antimicrobial prescriptions.

KEY WORDS: antimicrobials, antimicrobial stewardship, medical prescriptions, healthcare-acquired infections, quality of health care.

\section{CORRESPONDENCE TO:}

GUSTAVO HIDEKI KAWANAMI, Comissão de Controle de Infecção Hospitalar, Hospital Estadual Bauru, Faculdade de Medicina de Botucatu, Bauru, SP, Brasil. Phone: +55 143103 7777. Email: gustavo.kawanami@me.com. 